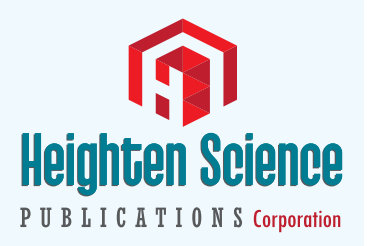

ISSN

2639-9938
*Address for Correspondence: Lucy Amanya Mutuli, Masinde Muliro University of Science and Technology, 190-50100, Kenya, Email: amanyalucy@yahoo.com

Submitted: 24 September 2018

Approved: 23 October 2018

Published: 24 October 2018

Copyright: (๑) 2018 Mutuli LA, et al. This is an open access article distributed under the Creative Commons Attribution License, which permits unrestricted use, distribution, and reproduction in any medium, provided the original work is properly cited

Keywords: Alcoholism; Physical activity; Psychosocial factors; Rehabilitation

Check for updates
Research Article

\section{Factors affecting physical activity of recuperating alcoholics in Asumbi- Homabay rehabiliation center, Kenya}

\author{
Lucy Amanya Mutuli*, Peter Bukhala and Gordon Nguka \\ Masinde Muliro University of Science and Technology, 190-50100, Kenya
}

\section{Abstract}

Background: Alcoholism is a widespread problem in Kenya and is associated with severe impacts on health and quality of life of the individual. Physical activity is an affordable and sustainable adjunct treatment option for recuperating alcoholics; however its' rarely used in rehabilitation of alcoholics in Kenya.

Objective: This qualitative study sought to elicit facilitators and barriers that influence the practice of physical activity amongst recuperating alcoholics under rehabilitation.

Methods: A focus group guide was utilized to gather views and perceptions of 15 alcoholics and 5 health professionals through focus group discussions. Constant comparative approach was used to analyze verbatim transcripts obtained from in-depth interviews. This analysis entailed three stages including open, axial and selective coding.

Results: Recuperating alcoholics' recognized various forms of physical activity to promote mental and physical health during their rehabilitation. Health professionals and significant others considerably supported the recuperating alcoholics to practice physical activity however physical activity facilities and facilitation was lacking in Asumbi rehabilitation center.

Conclusion: The rehabilitation centres should have physical activity experts and facilities that can offer individualized physical activity services and support needed by the recuperating alcoholics.

\section{Introduction}

The long-term change that occurs on brain biochemistry as a result of alcoholism leads to a brain that is 'wired for alcohol addiction'; physical activity is a good strategy to help 'restart' the brain, break alcohol addiction and support the process of recovery [1]. Both structured and un-structured physical activity can have an anxiety-alleviating and depression-prevention effect through dopaminergic reinforcements [2]. In Kenya treatment remains expensive, especially for in-patients who are rehabilitated for three months before discharge. However the outcome of alcohol treatment reveals uncertainties through the relapse range of $60 \%$ to $90 \%$ after treatment $[3,4]$. Evidence shows that the emphasis on physical activity is very limited in these rehabilitation centers $[5,6]$. Yet it fosters healthy lifestyle changes that contribute to long-term maintenance of recovery from alcohol. This setback is associated with the factual information delivered by educational sessions usually grounded in professional expertise. These sessions have no input from the alcoholics but simply impose ideas that leave the alcoholic with mixed perceptions regarding physical activity in effectively treating alcoholism and reducing relapse [3]. Basically, the routine support offered and fact-based approaches currently employed have inadequately met alcoholics' physical activity needs during alcohol rehabilitation. Given that, health professionals of the rehabilitation centers devise physical activity information without considering alcoholics' cognitive and experiential aspects such as attitude, self efficacy, knowledge, social perceptions and control beliefs [7]. These psychosocial factors are significant in

How to cite this article: Mutuli LA, Bukhala P, Nguka G. Factors affecting physical activity of recuperating alcoholics in Asumbi-Homabay rehabiliation center, Kenya. J Addict Ther Res. 2018; 2: 028-035. https://dx.doi.org/10.29328/journal.jatr.1001008 
explaining how an alcoholic makes the intention to practice physical activity during alcohol rehabilitation [8]. For instance, an alcoholics' subjective likelihood about the likely outcomes of the physical activity determines their attitude towards it. Moreover, alcoholics attempting to practice physical activity often fail as they have to comply with social expectations and encounter obstacles that may facilitate or impede their practice [9]. However, health professionals in rehabilitation centers may have ignored or may not be aware of these psychosocial factors when designing materials for promoting physical activity in treatment of alcoholism and reduction of relapse. An alcoholic' decision to practice physical activity is determined by a combination of psychosocial factors which need to be identified and assessed.

\section{Methods}

\section{Study area, design and population}

Asumbi-Homabay located in Homabay County, Nyanza region of Kenya formed the study area mainly because of the existence of Asumbi rehabilitation center. This center was purposively sampled with the target that it receives numerous alcoholic patients both males and females from different parts of the country, offers standardized rehabilitation services to alcoholic rehabilitees and it's accredited by NACADA. This cross-sectional study was conducted between January and March, 2017 at Asumbi rehabilitation center. Sample criteria included female and male alcoholics aged 15-65 years who were admitted not more than a week prior to commencement of the data collection and those who voluntarily consented to participate in the study. Alcoholics with active psychotic symptoms, addicts of substances other than alcohol and not intending to complete the three months of rehabilitation in Asumbi center were excluded from the study. A purposive sampling technique was used to select 20 out of 50 participants based on the inclusion criteria for this study, recommendations on qualitative research and utility of the TPB, and limitation of resources. The participants were elucidated for the purpose of the study before their participation in the in-depth interviews. Ethical approval was given by National Council for Science and Technology. Research authorization was granted by the National Agency for the Campaign against Drug Abuse, and Asumbi rehabilitation center. We sought informed consent from the respondents who were informed on the research procedures, details and assured of confidentiality.

\section{Study instrument}

An in-depth interview was conducted using a question guide developed based on Ajzen's theoretical framework. The main theme explored during the in-depth interview was psychosocial factors affecting practice of physical activity during alcohol rehabilitation. A total of 8 health professionals who were engaged in rehabilitating alcoholics at Asumbi Center were purposively selected and interviewed, the findings of these interviews were used to construct a question guide for the study. Two physical fitness experts and a researcher then critically examined, discussed and provided inputs into the content of the question guide; they also assisted in refining it. The question guide was then pretested on a sample of 5 alcoholics under rehabilitation at Asumbi Center who were randomly selected. The question guide was utilized to solicit information through in-depth interviews in groups consisting 15 alcoholics and 5 health professionals until saturation point. Verbatim transcripts were prepared regarding the factors these alcoholics encountered during their practice of physical activity while on rehabilitation. The procedure of preparing verbatim transcripts was essential to determine the salient consequences, significant referents and circumstances that form the belief structure underlying the intention to practice physical activity while on alcohol rehabilitation.

\section{Data analysis}

Constant comparative approach grounded in the Theory Planned Behaviour was 
used to analyze verbatim transcripts obtained from in-depth interviews. This analysis entailed three stages including open, axial and selective coding. In the open coding phase, verbatim transcripts generated during the in-depth interviews were examined and updated by listening to tapes to identify outstanding categories of information. In axial phase, the inductive coding categories were saturated and a set of categories developed where we identified several categories from the open coding list that were compared across to explore themes. The central phenomenon of interest was positioned at the centre of the theory and linked with other categories. In the selective phase, the inductive coding obtained was then organized into a coding paradigm that presents a theoretical model of the process under investigation.

\section{Results}

The interview responses provided a detailed source of information about behavioral beliefs, normative beliefs and control beliefs. Constant comparative approach analysis identified familiar verbatim transcripts on salient consequences (advantages/disadvantages), social referents (approval/disapproval) and circumstances (facilitator/barrier).

\section{Attitudinal beliefs affecting physical activity in alcohol rehabilitation}

Participants were informed of the importance of physical activity particularly to their alcohol rehabilitation. These beliefs included advantages and disadvantages of work activities in reference to alcohol rehabilitation. The benefit of work activities during alcohol rehabilitation was reported subsequently. Significantly, 17(87\%) of the participants reported that work activities 'increased energy expenditure above basal level', thus 'improving muscle strength' 12(62\%), 'reducing depression and anxiety' $10(50 \%)$. However it was acknowledged by the participants that work activity was 'activity occupational' 15(75\%), and 'decreased the urge to drink alcohol' 15(75\%). The only disadvantage reported of active activity is that it was 'tiring' $17(87 \%)$. Sports and games activities were considered to have numerous advantages as compared to other activities. It was reported that sports and games activities 'triggered dopaminergic reinforcement' $12(62 \%)$, 'improved brain chemistry' $7(37 \%)$, thus 'breaking the cycle of alcohol addiction' 10 (50 percent). Additionally, 5(25\%) of the participants reported it to enhance 'stabilization of blood sugars' thus 'decreasing fatigue' $10(50 \%)$. There were also other perceived benefits as reported by participants such as 'reducing brain cells killed by alcohol' 7(37\%), 'improves muscle tone' $7(37 \%)$, and 'replaces unrealistic rewards provided by alcohol' $10(50 \%)$. The aspect of costs was majorly mentioned as described in the disadvantages of sport and games activities. 'It requires facilities' reported by $15(75 \%)$, 'it needs trained expert', reported by $12(62 \%)$, 'it's expensive' $17(87 \%)$ and 'reduces alcohol socialization', described by $17(87 \%)$ of the participants. Leisure activities which were both passive and active were also considered. This finding have been summarised in table 1.

\section{Normative Beliefs affecting practice of physical activity in alcohol rehabilitation}

Normative beliefs are the social expectations of important people in the alcoholic's life regarding physical activities. Basically it was noted that family members had a greater influence on participants' decision to practise both work and sport activities while friends significantly promoted leisure activities both passive and active. Approximately 15(75\%) of the participants reported 'family members' as people whose opinion was most influential on alcoholic's decision to engage work activities, 'health professionals' and 'environment' were also reported to have a similar influence $12(62 \%)$ on the alcoholics. The 'friends' $10(50 \%)$ and 'colleagues' $7(37 \%)$ had a disapproving influence on work as an activity alcoholics should be engaged in. The practice of sport activities was appreciated by the participants who reported 'family members' $15(75 \%)$ to have a greater influence on their practice. The participants further reported that 'health professionals' 12(62\%) and 'friends' $10(50 \%)$ also encouraged them to be engaged in sport activities in order to enhance their recovery from alcoholism. The 'environment' $12(62 \%)$ had a greater influence in discouraging the alcoholics from engaging in sport activities. The alcoholics' 'friends' 17(87\%) were 
Table 1: Attitudinal beliefs affecting physical activity in alcoholism rehabilitation.

\begin{tabular}{|c|c|c|}
\hline Attitudinal Factors & Response (\%) & Frequency $(n=20)$ \\
\hline \multicolumn{3}{|l|}{ Advantages } \\
\hline \multicolumn{3}{|l|}{ Work Activities } \\
\hline Decreases the urge to drink alcohol & 75 & 15 \\
\hline Reduces depression and anxiety & 50 & 10 \\
\hline Increases energy expenditure above the basal level & 87 & 17 \\
\hline Its activity occupational & 75 & 15 \\
\hline Improves muscle strength & 62 & 12 \\
\hline \multicolumn{3}{|l|}{ Disadvantages } \\
\hline \multicolumn{3}{|l|}{ Work Activities } \\
\hline Its tiring & 87 & 17 \\
\hline \multicolumn{3}{|l|}{ Advantages } \\
\hline \multicolumn{3}{|l|}{ Sports and Games Activities } \\
\hline Break the cycle of alcohol addiction & 50 & 10 \\
\hline Triggers pleasurable states (dopaminergic reinforcement) & 62 & 12 \\
\hline Reduces brain cells killed by alcohol & 37 & 7 \\
\hline Improves muscle tone & 37 & 7 \\
\hline Decreases fatigue & 50 & 10 \\
\hline Improves brain chemistry & 37 & 7 \\
\hline Stabilizes blood sugar & 25 & 5 \\
\hline replace unrealistic rewards that provided by alcohol & 50 & 10 \\
\hline \multicolumn{3}{|l|}{ Disadvantages } \\
\hline \multicolumn{3}{|l|}{ Sport and Games Activities } \\
\hline Increases energy expenditure above the basal level & 62 & 12 \\
\hline It requires facilities & 75 & 15 \\
\hline It requires trained expert & 62 & 12 \\
\hline It is expensive & 87 & 17 \\
\hline Reduces alcohol socialization & 87 & 17 \\
\hline \multicolumn{3}{|l|}{ Advantages } \\
\hline \multicolumn{3}{|l|}{ Leisure activities } \\
\hline Improve mood management & 62 & 12 \\
\hline Strengthens self confidence & 62 & 12 \\
\hline replace the unrealistic rewards that provided by alcohol & 50 & 10 \\
\hline \multicolumn{3}{|l|}{ Disadvantages } \\
\hline \multicolumn{3}{|l|}{ Active Leisure activities } \\
\hline May trigger alcohol urge & 87 & 17 \\
\hline Requires management & 62 & 12 \\
\hline
\end{tabular}

Note: The total frequency does not add up to 20 because participants listed several items for each question addressing beliefs.

also very supportive to the idea of engaging in leisure activities, which was opposed by the 'environment' 15(75\%). These findings have been summarized in table 2.

\section{Control beliefs affecting practice of physical activity in alcohol rehabilitation}

Factors that may encourage/discourage work, sport and leisure activities were subsequently reported by the participants (Table 3). It was remarked that 'knowledge on importance of being active in rehabilitation' and 'alcoholic's health after the period of alcoholism' were equally significant facilitators of being engaged in work as reported by participants $12(62 \%)$ respectively. However participants were informed that 'availability of activities' $17(87 \%)$ was a very significant facilitator that enhanced their engagement in work activities. The barriers of involving in work activity was reported as 'rehab policy' $17(87 \%)$ and 'alcoholic health status' 15(75\%). A few participants $10(50 \%)$ reported that 'lack of assigned work' was also a barrier to engagement in work activities at the rehab. Participants reported 'physical activity knowledge in alcoholism' $12(62 \%)$ and 'alcoholic physical activity status' $10(50 \%)$ to have significant influence on alcoholic's decision to engage in sport and games activities. It was clear that participants were informed on the importance of sport and games activities to their health and especially in the recovery from alcoholism. The significant barriers of sport and games activities were reported as lack of motivation to engage in the activities' $17(87 \%)$ and 'lack of a trained expert in rehab' 17(87\%). It was further reported that 'inaccessibility to sports activity facilities' $17(87 \%)$ was also reported 
Table 2: Normative Beliefs affecting practise of physical activity during rehabilitation.

\begin{tabular}{|c|c|c|}
\hline Beliefs & Responses (\%) & Frequency $n=20$ \\
\hline \multicolumn{3}{|l|}{ Normative Beliefs } \\
\hline \multicolumn{3}{|l|}{ Work Activities } \\
\hline \multicolumn{3}{|l|}{ Approval } \\
\hline Health professionals & 62 & 12 \\
\hline Family members & 75 & 15 \\
\hline Environment (others) & 62 & 12 \\
\hline \multicolumn{3}{|l|}{ Disapproval } \\
\hline Friends & 50 & 10 \\
\hline Colleagues & 37 & 7 \\
\hline \multicolumn{3}{|l|}{ Sports Activities } \\
\hline \multicolumn{3}{|l|}{ Approval } \\
\hline Health professionals & 62 & 12 \\
\hline Family Members & 75 & 15 \\
\hline Friends & 50 & 10 \\
\hline Colleagues & 37 & 7 \\
\hline \multicolumn{3}{|l|}{ Disapproval } \\
\hline Environment & 62 & 12 \\
\hline \multicolumn{3}{|l|}{ Active Leisure Activities } \\
\hline \multicolumn{3}{|l|}{ Approval } \\
\hline Medical professionals & 50 & 10 \\
\hline Family members & 62 & 12 \\
\hline Friends & 87 & 17 \\
\hline Colleagues & 50 & 10 \\
\hline \multicolumn{3}{|l|}{ Disapproval } \\
\hline Environment & 75 & 15 \\
\hline
\end{tabular}

Note: The total frequency does not add up to 20 because participants listed several items for each question addressing beliefs.

Table 3: Control Beliefs affecting Practice of Physical Activity in Alcohol Rehabilitation.

\begin{tabular}{|c|c|c|}
\hline Control Beliefs & Response (\%) & Frequency $(n=20)$ \\
\hline \multicolumn{3}{|l|}{ Work Activities } \\
\hline \multicolumn{3}{|l|}{ Facilitators } \\
\hline Knowledge of being active in rehabilitation & 62 & 12 \\
\hline Availability of activities & 87 & 17 \\
\hline Alcoholic's health after the period of alcoholism & 62 & 12 \\
\hline \multicolumn{3}{|l|}{ Barriers } \\
\hline Rehab Policy & 87 & 17 \\
\hline Alcoholic's health status & 75 & 15 \\
\hline Lack of assigned work & 50 & 10 \\
\hline \multicolumn{3}{|l|}{ Sport Activities } \\
\hline \multicolumn{3}{|l|}{ Facilitators } \\
\hline Physical activity knowledge in alcoholism & 62 & 12 \\
\hline Alcoholic's physical activity status & 50 & 10 \\
\hline \multicolumn{3}{|l|}{ Barriers } \\
\hline Lack of fitness expert in the rehab & 87 & 17 \\
\hline inaccessibility to sport activity facilities and equipment & 87 & 17 \\
\hline Lack of motivation to engage in physical activity & 87 & 17 \\
\hline \multicolumn{3}{|l|}{ Active Leisure Activities } \\
\hline \multicolumn{3}{|l|}{ Facilitators } \\
\hline Adequate time & 50 & 10 \\
\hline Motivation to engage & 62 & 12 \\
\hline \multicolumn{3}{|l|}{ Barriers } \\
\hline Lack of sport and games facilities & 87 & 17 \\
\hline
\end{tabular}

Note: Total frequency does not add up to 20 because participants listed several items for each question addressing beliefs.

as barrier to sports and games activities. This finding reveals that the rehabilitation center was lacking sport and games activities schedules, facilities and the experts to facilitate the activities during alcohol rehabilitation.

\section{Discussion}

The recuperating alcoholics appreciated the health benefits of practicing physical activity in facilitating their complete recovery from alcoholism. Engaging in work related duties, sports and games, active leisure activities were regarded as forms 
of physical activities for their optimal rehabilitation. Involving in physical activities was regarded to increase energy expenditure above the basal level, reduced the urge to alcohol intake and it was also occupational. Similarly, previous studies have demonstrated that physical activities might promote mental and physical health in persons with alcohol use disorders [10-12]. In addition Zschucke Heinz, \& Ströhle, indicated that physical activities might reduce drinking episodes and craving, while improving psychological outcomes like depression, anxiety and increasing physical fitness. This was supported by previous past studies that suggested physical activity as a potentially useful and relatively unexplored alternative behavior for alcoholics working towards long-term recovery $[13,14]$. As illustrated in table 2 , the practice of physical activity by recuperating alcoholics was encouraged by health professionals and family members who were concerned about their recovery from alcoholism. The influences from these significant referents did show to affect the participants' decision on practise of physical activity during alcohol rehabilitation as displayed in table 2. National Institute of Clinical Health and Excellence, (2011) [15] argues that the relationship between physical activity participation and professional or family support is a dynamic process in which the sources of support or need for support changes, and social barriers can be addressed by involving influential others in the rehabilitation process. This has fundamental implications for clinical practice of health professionals and also family members, who should capitalize on this finding to encourage alcoholics on rehabilitation to include various forms of physical activities during their rehabilitation and maintain it even after discharge from the centre. Social norms are the behavioral standards that exist in a social group for what is considered correct and appropriate behavior, and they emerge from the shared practices and expectations of the group members. When social and environmental support systems are in place, making healthful choices becomes possible and has an opportunity to improve alcohol rehabilitation. Perceived behavioral control represented participant's perceptions of control over practice of physical activity in the face of internal and external barriers; and the self-efficacy i.e., confidence that the participants have the ability to practice physical activity intake in spite of obstacles. In Asumbi rehabilitation center, the institution policy denied the recuperating alcoholics the consent to be involved in work related activities since they were workers employed to perform such activities. Further to this, the institution lacked sufficient games and sports facilities for these recuperating alcoholics to be involved. In concurrence, previous studies have reported that most of the rehabilitation centres in Kenya have not prioritized physical activity as an adjunct to the treatment of alcoholism [4,7]. This is a wakening call to the rehabilitation centres who should consider physical activity as an important aspect in the treatment of recuperating alcoholics since it a lifestyle habit which recuperating alcoholics can adapt and sustain even after discharge from the centre. Data suggested that low motivation may also be a substantial barrier to engaging in physical activity amongst recuperating alcoholics with high self efficacy. This implies that motivational enhancement approaches should be emphasized in successful rehabilitation from alcoholism. In conclusion, this qualitative section revealed the factors affecting the practice of physical activity amongst recuperating alcoholics of Asumbi rehabilitation centre. The understanding of these significant factors provided a foundation for quantitative research that confirmed the influence of these factors on the practice of physical activity during alcohol rehabilitation.

\section{Conclusion}

This qualitative study ascertains that scarcity of physical activity facilities and facilitation was a major barrier to the practise of physical activity during alcohol rehabilitation. This establishes mixed perceptions on the recuperating alcoholics on how they can maintain active lifestyles during rehabilitation. Fostering strong combined relationships amongst 
family members and health professionals is fundamental to support physical activity of an alcoholic on recuperation. The rehabilitation centres should have physical activity experts and facilities that can offer individualized physical activity services and support needed by the recuperating alcoholics. Physical activity alone is insufficient to keep an alcoholic sober and self-reported perception of self efficacy and optimal dietary intake included, may predict long-term abstinence. Physical activity during alcohol rehabilitation is a pathway that reflects self-care, commitment to staying sober and is a vital adjunct in the complete recovery from alcoholism and reduction of relapse [16]. This may reduce the prevalence of alcohol relapse after discharge from the rehabilitation centre.

\section{Acknowledgment}

The authors sincerely thank participants who shared their experiences, and contributed needed information to the study. All those contributed to the success of this study in one way or another are also recognized.

\section{Authors' contributions}

All authors were involved with the drafting of the research paper, critically reviewed the manuscript and approved the final version submitted for publication.

\section{References}

1. Sinclair J, Chick J, Sørensen P, Kiefer F, Batel P, et al. Can Alcohol Dependent Patients Adhere to An 'as Needed' Medication Regimen? European Addict Research. 2014; 20: 209-217. Ref.: https://goo.gl/eTvVZE

2. Sari S, Bilberg. R, Kurt J, Søgaard-Nielsen A, Nielsen B, et al. Physical Exercise as a Supplement to Outpatient Treatment of Alcohol use Disorders a Randomized Controlled Trial. BMC Psychology. 2013; 1:23. Ref.: https://goo.gl/AUESXX

3. Chesang RK. Drug Abuse among the Youth in Kenya. International Journal of Scientific \& Technology Research. 2013; 2; 2277-8616. Ref.: https://goo.gl/gF54ja

4. Kuria MW. Factors Associated with Relapse and Remission of Alcohol Dependent persons after Community Based Treatment. Open Journal of Psychiatry. 2013; 3: 264-272. Ref.: https://goo.gl/xRMVqM

5. Chepkwony SJ, Chelule E, Barmao AC. An Investigation into Prevalence and Factors Contributing to Relapse among Alcoholics In Selected Rehabilitation Centers in Nairobi County, Kenya. International Journal of Innovative Research and Development. 2013; 2: Ref.: https://goo.gl/Zzxj1P

6. Kahuthia-Gathu R, Okwarah P, Gakunju R, Thungu J. Trends and Emerging Drugs in Kenya: A Case Study in Mombasa and Nairobi County. Journal of Applied Biosciences. 2013; 67: 5308-5325. Ref.: https://goo.gl/gjHWxN

7. Langat E, Wafula S, Ettyang G, Rotich J, Chelimo J, The Effect of Rehabilitation on Nutritional Status of Alcohol Dependent Males in Nairobi, Kenya. Journal of Biology, Agriculture and Healthcare. 2014 4: Ref.: https://goo.gl/JDj3C5

8. Ajzen I. The Theory of Planned Behavior, Organizational Behavior and Human Decision Process. Journal of Applied Social Psychology. 1991; 50: 179 -211. Ref.: https://goo.gl/dmN5eU

9. Mathew RJ. Eating to Prevent Alcohol Cravings and Relapse. 2016; Ref.: https://goo.gl/ssy7m1

10. Brown RA, Abrantes AM, Read JP, Marcus BH, Jakicic J, et al. Aerobic Exercise for Alcohol Recovery: Rationale, Program description, and Preliminary findings. Behavior Modification. 2009; 33: 220-249. Ref.: https://goo.gl/tCGCnw

11. Karoly HC, Stevens CJ, Thayer RE, Magnan RE, Bryan AD, et al. Aerobic Exercise Moderates the Effect of Heavy Alcohol Consumption on White Matter Damage. Alcoholism, Clinical and Experimental Research. 2013; 37: 1508-1515. Ref.: https://goo.gl/1KXADR

12. Zschucke E, Heinz A, Ströhle A. Exercise and Physical Activity in the Therapy of Substance use Disorders. Scientific World Journal. 2012; 901741. Ref.: https://goo.gl/zEdkYe

13. French MT, Popovici I, Maclean JC. Do Alcohol Consumers Exercise more? Findings from a National Survey. Journal of Infection. 2009 24: 2-10. Ref.: https://goo.gl/SN59gX

14. Smothers B, Bertolucci D. Alcohol Consumption and Health-promoting Behavior in a US Household 
Sample: Leisure-time Physical Activity. J Stud Alcohol. 2001; 62: 467-476. Ref.: https://goo.gl/Du9CH5

15. National Institute of Clinical Health and Excellence. Alcohol-use Disorders: Diagnosis, Assessment and Management of Harmful drinking and Alcohol Dependence. London: National Institute of Clinical Health and Excellence. 2011;

16. McEachan RRC, Conner M, Taylor NJ, Lawton RJ. Prospective Prediction of Health-Related Behaviors with the Theory of Planned Behavior: A meta-analysis. Health Psychology Review. 2001; 5: 97-144. Ref.: https://goo.gl/ePyw6d 